\title{
Remarkable Miscibility Between Disk- and Lath-like Mesogens
}

Gaël Zucchi, ${ }^{,+\dagger}$ Bertrand Donnio, ${ }^{+}$Yves H. Geerts ${ }^{*}+\dagger$

Supporting Information (3 pages including this one) 
Table F1. X-ray characterization of the mesophases of 1 at $100^{\circ} \mathrm{C}, 2$ at 100 and $200^{\circ} \mathrm{C}$ and $\mathbf{3}$ at $100^{\circ} \mathrm{C}$.

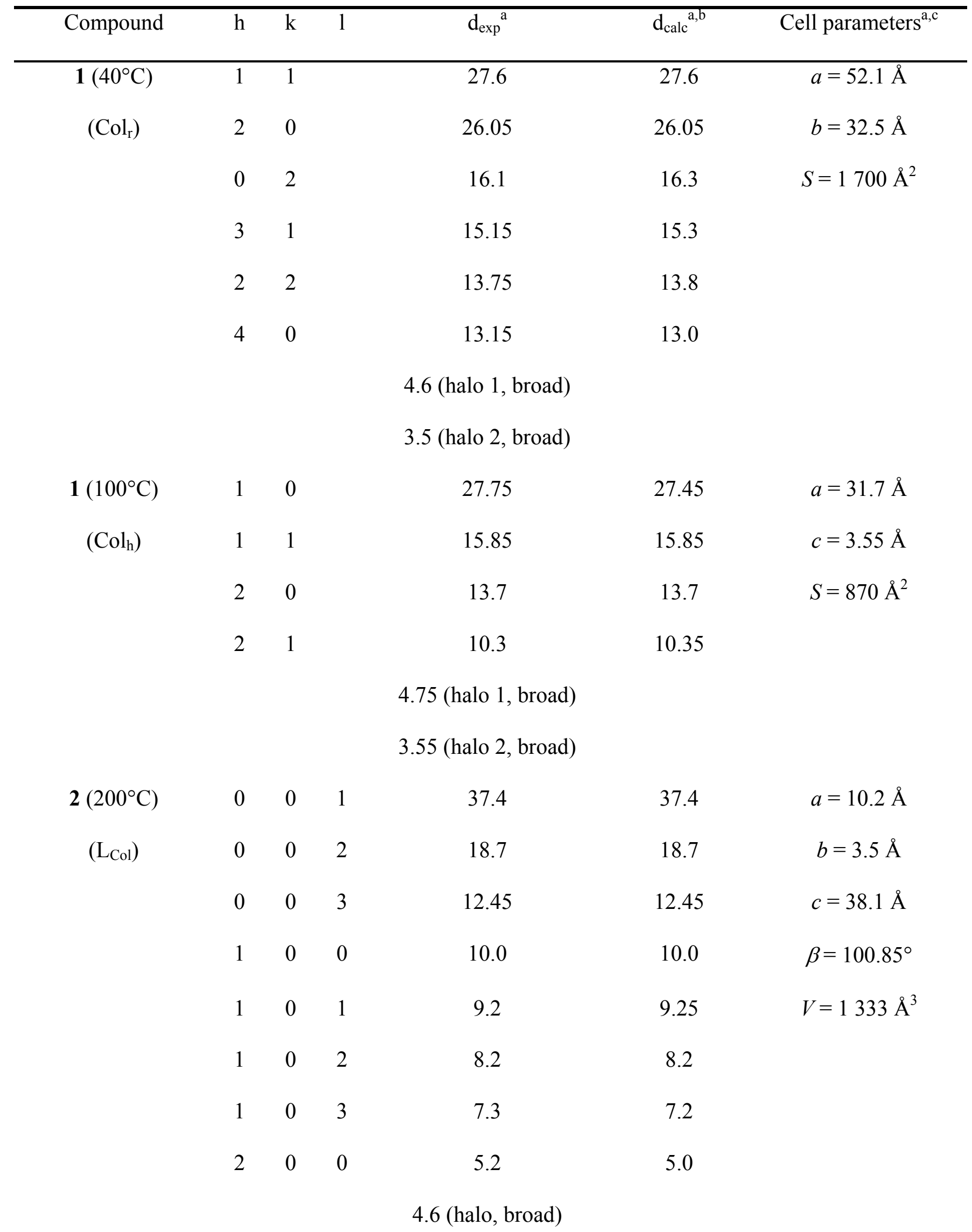




$\begin{array}{ccccccc} & 0 & 1 & 0 & 3.5 \text { (sharp) } & 3.40 & \\ \mathbf{2}\left(100^{\circ} \mathrm{C}\right) & 0 & 0 & 1 & 35.2 & 34.75 & a=34.75 \AA \\ \mathrm{Cr}_{\text {Lam }} & 0 & 0 & 2 & 17.25 & 17.35 & \\ & 0 & 0 & 3 & 11.5 & 11.6 & \\ \mathbf{3}\left(100^{\circ} \mathrm{C}\right) & 1 & 0 & 27.9 & 27.7 & a=32.0 \AA \\ \left(\mathrm{Col}_{\mathrm{h}}\right) & 1 & 1 & 16.0 & 16.0 & c=3.4 \AA \\ & 2 & 0 & 13.8 & 13.85 & S=885 \AA^{2} \\ & 2 & 1 & 10.45 & 10.45 & \\ & & & \text { 4.6 (halo 1, broad) } & & \end{array}$

[a] Distances and cell parameters are given in $[\AA]$.

[b] $d_{\exp }$ and $d_{\text {calc }}$ are the experimentally measured and calculated diffraction spacings. $d_{\text {calc }}$ is deduced from the following mathematical expressions: for the $\mathrm{L}_{\mathrm{Col}}$ phase $\left\langle d_{001}\right\rangle=\frac{1}{N_{l}}\left(\sum_{l} d_{00 l} l\right)$, where $N_{l}$ is the number of $00 l$ reflections, the other theoretical $d_{h o l}$ spacings were determined considering a monoclinic lattice; for the $\mathrm{Col}_{\mathrm{h}}$ phase $\left\langle d_{10}\right\rangle=\frac{1}{N_{h k}}\left(\sum_{h, k} d_{h k} \cdot \sqrt{h^{2}+k^{2}+h k}\right)$, where $N_{h k}$ is the number of $h k$ reflections; for the $\mathrm{Col}_{\mathrm{r}}$ phase, the calculated $d_{11}$ and $d_{20}$ are the measured one, whereas all the other theoretical reflections were obtained considering an orthorhombic lattice. $a, b, c$, and $\beta$ are the parameters of the monoclinic cell of the $\mathrm{L}_{\mathrm{Col}}$ phase. $a$ is the lattice parameter of the $\operatorname{Col}_{\mathrm{h}}$ phase $\left(a=\frac{2}{\sqrt{3}}\left\langle d_{10}\right\rangle\right)$, and $S$ is the lattice area $\left(S=a\left\langle d_{10}\right\rangle \cdot a, b\right.$ are the parameters of the $\mathrm{Col}_{\mathrm{r}}$ phase, and $S=a . b$ the lattice area $\left(A=\sqrt{\frac{2}{\frac{1}{d_{11}^{2}}+\frac{1}{d_{1 \overline{1}}^{2}}-\frac{1}{2 d_{20}^{2}}}} ; a=2 d_{20} ; b=A\right)$. 